\title{
New Concepts of Dense set in i-Topological space and Proximity Space
}

\section{Yiezi Kadham Mahdi AL Talkany ${ }^{1}$, Luay A.A.AL-swidi ${ }^{2}$}

${ }^{1}$ Department of mathematics, college of education for girle university of kufa, Najaf , iraq yieziK.alTalkany@uokufa.edu-iq,

${ }^{2}$ Department of mathematics ,college of education for pure science, Babylon university, Babylon , Iraq pure.leal.abd@uobabylon.edu.iq

Article History:Received:11 January 2021; Accepted: 27 February 2021; Published online: 5 April 2021

Abstract: A new kind of some topological spaces concepts has been defined in i-topological spaces with respect to proximity spaces in our paper.

Keywords: i-topological spaces $\oint_{\text {-dense ,i-dense, }} \mathcal{F O}$ dense ${ }_{\text {, focal resolvable, ,ideal link }}$

\section{Introduction}

In 1909 Riecs [10] introduce the concept of proximity relation then this concept was developed by Efremovic in 1952 [21] as this concept has been used on a large scale to produce a huge amount of different research in various disciplines like [3,4,8,11] After Kartowski's definition[9] of ideal in 1933 and his definition of ideal topological spaces which includes two structures, the ideal I and topological space (X,T), these concepts played a major role in the development of researches for a large number of researchers in various studies like $[2,5,6]$. A new topology for $\mathrm{X}$ has been constructed from the family $\mathrm{T}$ and the ideal I defined by Irina [6] and its called the i-topological space which includes checked the following condition (1) $\emptyset, \mathrm{X} \in \mathrm{T}$,(2)for any $\mathrm{U} \subseteq \mathrm{T}_{\text {there exist }} \mathrm{U} \in \mathrm{T}_{\text {such that }} \mathrm{UU} \approx \mathrm{U} \quad$ (3)for each $\mathrm{V}, \mathrm{W} \in \mathrm{T}_{\text {there exist }} \mathrm{U} \in \mathrm{T}_{\text {such that }}$

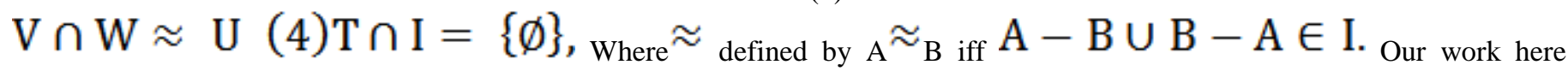
includes studying the influences that can appear on some topological characteristics in i-topolgical space through their application using the proximity theory, and among these characteristics are: adherent point, density, resolvability as it was relying on some concepts that were presented in previous research [20]

\section{Preliminaries}

Definition (2-1) [20]:

let $(\mathrm{X}, \mathrm{T}, \mathrm{I})$ be a space then a subset, $\mathrm{A}$ of $\mathrm{X}$ is called focal set if there exist

$\mathrm{U} \in \mathrm{T}(\mathrm{x}), \mathrm{x} \in \mathrm{X}_{\text {such that }} \mathrm{U} \alpha \mathrm{A}_{\text {, where }} \mathrm{U} \alpha \mathrm{A}_{\text {means that }} \mathrm{U}-\mathrm{A} \in \mathrm{I}_{\text {and }} \mathrm{I}_{\oint}(\mathrm{x})_{\text {denoted the set of all focal }}$ set of the point $\mathrm{X}$.

Definition (2-2)[20] :

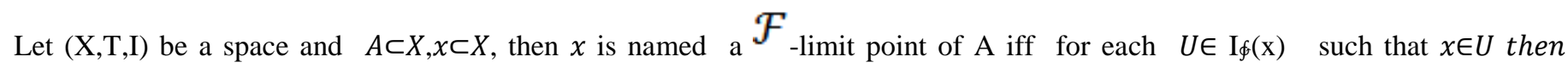
$(U x \cap A)-\{x\} \neq \varnothing$ and the set of all a limit point of $A$ is named the focal derived set and denoted by $\mathcal{F} \mathrm{d}_{(\mathrm{A}) \text {, and }}$

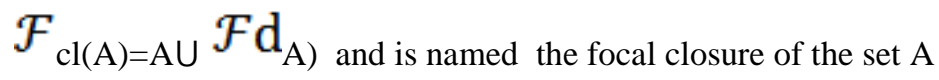

Definition (2-3) [20]:

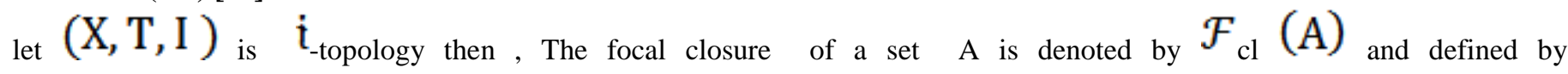
$\mathcal{F} \mathrm{cl}(\mathrm{A})=\mathrm{A} \cup \mathcal{F} \mathrm{d}(\mathrm{A})_{\text {where }} \mathcal{F} \mathrm{d}(\mathrm{A})_{\text {Is the set of all focal limit points of the set A }}$

Definition (2-4) [20]:

let $(\mathrm{X}, \mathrm{T}, \mathrm{I})_{\text {be a space and }} \mathrm{A} \subseteq \mathrm{X}_{\mathrm{Then}} \mathrm{i}-\mathrm{cl}(\mathrm{A})$ is the intersection of all 
Research Article

i. closed sets suppress of A.

Definition (2-5): [20]

let $(\mathrm{X}, \mathrm{T}, \mathrm{I})$ be a space and $(\mathrm{X}, \delta)$ is a proximity space and $\mathrm{B} \subseteq \mathrm{X}$ then a point

$\mathrm{x} \in \mathrm{X}$ is called occlusion point of $\mathrm{B}$ if for each $\mathrm{U} \in \mathrm{I}_{\oint}(\mathrm{x}), \mathrm{x} \in \mathrm{U}, \mathrm{U} \delta \mathrm{B} \oint(\mathrm{B})_{\text {denoted the set of }}$ all occlusion points of $\mathrm{B}$.

. Definition (3-1) :

I. III - FOCAL ADHERENT POINT

let $(\mathrm{X}, \mathrm{T}, \mathrm{I})_{\text {is }} \mathrm{i}_{\text {-Topological space and }}(\mathrm{X}, \delta)$ is a proximity space then a point $\mathrm{x} \in \mathrm{X}$ is called Focal adherent point of a subset $A$ of $X$ iff for each $U \in I_{\oint}(x), U \cap A \neq \emptyset_{\text {and is denoted by }} \mathcal{F}_{\text {adh }}(\mathrm{A})$.

now a relationship between $\mathcal{F}_{\mathrm{d}}(\mathrm{A}), \mathcal{F}_{\text {adh(A), }} \oint_{\text {(A), Fcl (A) as follows in the following proposition }}$

Proposition (3-2) :

let $(\mathrm{X}, \mathrm{T}, \mathrm{I})$ is $\dot{\mathbf{I}}_{\text {- Topological of space and }}(\mathrm{X}, \delta)$ is a proximity space and let A is a subset of $\mathrm{X}$ then each of the following are holds :

1. $\mathcal{F}_{\mathrm{d}}(\mathrm{A}) \subseteq \mathcal{F}_{\mathrm{adh}(\mathrm{A})} \subseteq \oint$

2. $\mathcal{F}_{\mathrm{adh}(\mathrm{A})} \subseteq_{\mathrm{Fcl}(\mathrm{A})}$

3. If $\mathrm{A} \in \mathrm{I}_{\oint(\mathrm{x}) \text {, then }} \mathcal{F}_{\text {adh(A) }}={ }_{\mathrm{X}}$

4. If A $\in I_{\text {then }} \mathcal{F}_{\text {adh }}(\mathrm{A})=\emptyset$

Proof (4)

let $x \in \in_{\mathrm{X}}$ if possible that $\mathrm{x} \notin \mathcal{F}_{\text {adh }}(\mathrm{A})$, so there exist $\mathrm{U} \in \mathrm{I}_{\oint} \mathrm{x}_{\text {) such that }}$

$\mathrm{U}_{\mathrm{A}}=\emptyset$ but this mean that $\left.\emptyset \in \mathrm{I}_{\oint} \mathrm{x}\right)_{\text {this contradiction. }}$

The following example shows that the convers is not true

Example (3-3) :

Let $X={ }_{\{a, b, c\}, T}={ }_{\{X,} \emptyset_{, a, b\},\{a, c\}\},} I=\{\emptyset,\{c\}\}_{\text {and }} A=\{a, c\}_{\text {then }}$

$\mathcal{F}_{\text {adh }}\{\mathrm{a}, \mathrm{c}\}=\mathrm{X}_{\text {but }} \mathrm{A} \notin \mathrm{I}_{\oint}(\mathrm{b})_{\text {and for }} \mathrm{B}=\{\mathrm{b}\}_{\text {Then }} \mathcal{F}_{\text {adh }\{\mathrm{b}\}}=\emptyset_{\text {but }\{\mathrm{b}\}} \notin \mathrm{I}$

Definition (4-1) :

IV - SOME TYPES OF DENSITY

let $(\mathrm{X}, \mathrm{T}, \mathrm{I})_{\text {is }} \mathrm{i}_{\text {-Topological space and }}(\mathrm{X}, \delta)$ is a proximity space and $\mathrm{A} \subseteq_{\mathrm{X} \text { Then A is called }}$

1) $\mathrm{i}_{\text {-dense iff }} \mathbf{i}_{-\operatorname{cl}(\mathrm{A})}={ }_{X}$

2) Focal dense iff $\mathcal{F}_{\mathrm{cl}(\mathrm{A})}=_{\mathrm{X} \text { and is denoted by }} \mathcal{F} \mathrm{O}_{\text {dense }}$

3) $\oint_{\text {-dense iff }} \oint_{(\mathrm{A})}=_{\mathrm{X}}$.

we obtain a relationship that connect both $\mathcal{F} \boldsymbol{O}_{\text {dense, }} \oint_{\text {-dense and i-dense as in the following }}$

Proposition (4-2) :

Let $(\mathrm{X}, \mathrm{T}, \mathrm{I})_{\text {is }} \mathrm{i}_{\text {-Topological space and }}(\mathrm{X}, \delta)$ is aproximity space then

1. Every $\mathcal{F} \mathrm{O}_{\text {dense set is }} \oint_{\text {-dense }}$ 
Research Article

2. Every $\mathcal{F} \mathrm{O}_{\text {dense set is }} \mathrm{i}_{\text {- dense set }}$

The following example shows that the converse of above Proposition is not true

Example : (4-3)

$\mathrm{x}={ }_{\{\mathrm{a}, \mathrm{b}, \mathrm{c}\}, \mathrm{T}}=\left\{\{\mathrm{X}, \emptyset,\{\mathrm{a}, \mathrm{b}\},\{\mathrm{a}, \mathrm{c}\}\}, \mathrm{I}=\{\emptyset,\{\mathrm{c}\}\}_{\text {,and } \mathrm{A}}=_{\{\mathrm{b}, \mathrm{c}\}}\right.$ then $\mathrm{A}$ is $\mathrm{i}$ - dense But not $\mathcal{F O}$ dense .

\section{Proposition (4-4) :}

Let $(\mathrm{X}, \mathrm{T}, \mathrm{I})_{\text {is }} \mathbf{i}_{\text {- Topological space and }}(\mathrm{X}, \delta)$ is a proximity space and $\mathrm{A}, \mathrm{B} \subseteq_{\mathrm{X}}$ then the following are holds:

1. $\mathrm{A} \subseteq_{\mathrm{B} \text { such that } \mathrm{A} \text { is }} \mathcal{F} \mathrm{O}_{\text {dense then } \mathrm{B} \text { is }} \mathcal{F} \mathrm{O}_{\text {dense }}$

2. If $\mathrm{A} \cap{ }_{\mathrm{B} \text { is }} \mathcal{F} \mathrm{O}_{\text {dense then } \mathrm{A}, \mathrm{B} \text { are }} \mathcal{F} \mathrm{O}_{\text {dense }}$

3. A, B are $\mathcal{F} \mathrm{O}_{\text {dense then } \mathrm{A}} \mathrm{U}_{\mathrm{B} \text { is }} \mathcal{F} \mathrm{O}_{\text {dense }}$

Proof: (1)

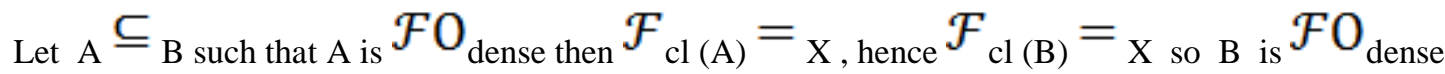

Example (4-5) :

$\mathrm{X}=\{\mathrm{a}, \mathrm{b}, \mathrm{c}\}, \mathrm{T}=\{\mathrm{X}, \emptyset,\{\mathrm{a}\}\}, \mathrm{I}=\{\emptyset\}_{\mathrm{A}}=_{\{\mathrm{b}\} \text { and } \mathrm{B}}={ }_{\{\mathrm{a}, \mathrm{b}\} \text { clearly that } \mathrm{A}} \subseteq_{\mathrm{B} \text { and }} \mathcal{F}_{\text {cl(B) }}=_{\mathrm{X}}$ But $\mathcal{F}_{\mathrm{cl}\{\mathrm{b}\}} \neq \mathrm{X}$

Example : (4-6)

$\mathrm{X}=\{\mathrm{a}, \mathrm{b}, \mathrm{c}\}, \mathrm{T}=\{\mathrm{X}, \emptyset,\{\mathrm{a}, \mathrm{b}\}\}_{\text {and }} \mathrm{I}=\{\emptyset\}_{\text {then } \mathrm{A}}=_{\{\mathrm{a}, \mathrm{c}\}, \mathrm{B}}=_{\{\mathrm{b}, \mathrm{c}\} \text { are }} \mathcal{F} \mathrm{O}_{\text {dense but }, \mathrm{A}} \cap_{\mathrm{B}}=$ \{c is not $\mathcal{F O} \mathrm{O}_{\text {dense. Also } \mathrm{H}}=_{\{\mathrm{b}\}, \mathrm{K}}=_{\{\mathrm{c}\}, \mathrm{H}} \mathrm{U}_{\mathrm{K} \text { is }} \mathcal{F} \mathrm{O}_{\text {dense but B is not }} \mathcal{F} \mathrm{O}_{\text {dense }}$

Remark : (4-7)

for each A in I, A is not $\mathcal{F} \mathrm{O}_{\text {dense }}$

Proposition : (4-8)

Let $(\mathrm{X}, \mathrm{T}, \mathrm{I}){ }_{\text {is }} \mathbf{i}_{\text {-Topological space and }}(\mathrm{X}, \delta)$ is a proximity space, the following properties are holds:

1. $A$ is $\dot{\mathbf{I}}_{\text {-dense iff }} \mathrm{U} \cap A \neq \emptyset$ for each $\in_{\mathrm{T}}$

2. A is $\mathcal{F} O_{\text {dense then }} \mathrm{U} \cap \mathrm{A} \neq \emptyset_{\text {for each } \mathrm{U}} \in_{\mathrm{T}}$

\section{Proof (1)}

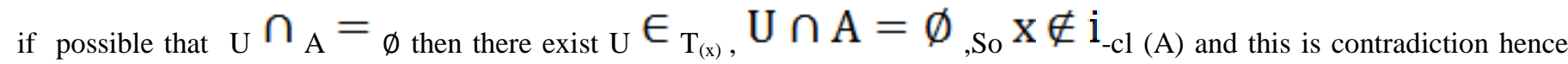

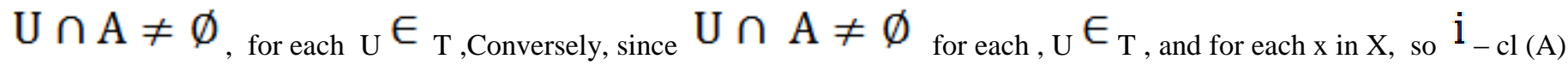
$={ }_{\mathrm{X}}$, hence, $\mathrm{A}$ is $\mathbf{i}$ - dense set

(2) the proof is similar to (1)

Example : (4-9)

$\mathrm{X}={ }_{\{\mathrm{a}, \mathrm{b}, \mathrm{c}\}, \mathrm{T}}=_{\{\mathrm{X}, \emptyset,\{\mathrm{a}, \mathrm{b}\},\{\mathrm{a}, \mathrm{c}\}\} \text { and }} \mathrm{I}=_{\{\varnothing,\{\mathrm{c}\}\} \text { for a proximity space }} \delta_{\text {defined by } \mathrm{A}} \delta \mathrm{B}$ iff $\mathrm{B} \cap \mathrm{A} \neq \emptyset$ if we take $\mathrm{A}={ }_{\{\mathrm{b}, \mathrm{c}\} \text { is not }} \mathcal{F} \mathrm{O}_{\text {dense we get that } \mathrm{U}} \cap_{\mathrm{A}} \neq_{\emptyset \text { for each }} \mathrm{U} \in \mathrm{T}$.

Example: (4-10)

$\mathrm{X}=\{\mathrm{a}, \mathrm{b}, \mathrm{c}\}, \mathrm{I}=\{\varnothing,\{\mathrm{a}\}\} \quad$ and $\quad \mathrm{T}=\{\mathrm{X}, \varnothing \quad\} \quad$ for $\quad \mathrm{a}$ proximity space $\delta_{\text {defined by }}$ ${ }_{\mathrm{A}} \delta \mathrm{B}$ iff $\mathrm{B} \cap \mathrm{A} \neq \emptyset$ clearly that $\mathrm{A}={ }_{\{\mathrm{a}\} \text { is not }} \oint_{\text {dense set but }}, \mathrm{U} \cap \mathrm{A} \neq \emptyset, \forall \mathrm{U} \in \mathrm{T}$ 
Research Article

\section{Proposition: (4-11)}

Let $\left(\mathrm{X}, \mathrm{T}, \mathrm{I}_{\text {) is }} \mathrm{i}_{\text {-Topological space and }}(\mathrm{X}, \delta)\right.$ is a proximity space, A is $\mathcal{F} \mathrm{O}_{\text {dense iff }} \mathcal{F}$ adh(A) ${ }_{\mathrm{X}}$

\section{Proof:}

Let $\mathrm{A}$ is $\mathcal{F} \mathrm{O}_{\text {dense if possible that }} \mathcal{F}_{\text {adh(A) }} \neq{ }_{\mathrm{X}}$ so there exist $\mathrm{x} \in \in_{\mathrm{X} \text { such that }} \mathrm{x} \notin \mathcal{F}_{\text {adh (A), and by (3-2)(1), } \mathrm{x} \notin}$

$\mathcal{F}_{\mathrm{d}(\mathrm{A}) \text { that we get there exist } \mathrm{U}} \in \mathrm{I}_{\oint}(x)_{, \mathrm{x}} \in_{\mathrm{U}, \mathrm{U}} \cap_{\mathrm{A}}=\varnothing$ and then $\mathrm{x} \notin_{\mathrm{A} \text {, from that we get }} x \notin \mathcal{F}_{\mathrm{cl} \text { (A) and }}$ this is contradiction by assume, hence $\mathcal{F}_{\text {-adh (A) }}={ }_{\mathrm{X}}$, Conversely, let $\mathcal{F}_{\text {adh (A) }}={ }_{\mathrm{X} \text { and by proposition (3-2) we get that }}$ A is $\mathcal{F} \mathrm{O}_{\text {dense }}$

Proposition (4-12) :

Let $\left(\mathrm{X}, \mathrm{T}, \mathrm{I}_{)}\right.$is $\mathrm{i}_{\text {-Topological space and }}(\mathrm{X}, \delta)$ is aproximity space, if A is $\mathcal{F} \mathrm{O}_{\text {dense then }} \mathcal{F}$ adh(A) $=\mathcal{F}$ cl (A) .

Example :(4-13)

Let $\mathrm{X}={ }_{\{\mathrm{a}, \mathrm{b}, \mathrm{c}\}, \mathrm{T}}=_{\{\mathrm{X}, \varnothing,\{\mathrm{a}\}\} \text { and }} \mathrm{I}=_{\{\varnothing,\{\mathrm{c}\}\} \text { when A }}=_{\{\mathrm{b}\} \text { then clearly that }} \mathcal{F}_{\mathrm{cl}(\mathrm{A})}=\mathcal{F}_{\text {adh (A) But A is not }}$ $\mathcal{F O}$ dense .

\section{Definition : (4-14)}

Let $\left(\mathrm{X}, \mathrm{T}, \mathrm{I}_{)}\right.$is $\mathrm{i}_{\text {-Topological space and }}(\mathrm{X}, \boldsymbol{\delta})$ is a proximity space then $\mathrm{X}$ is called :

1. $\mathrm{i}_{\text {-resolvable if there exist } \mathrm{A}, \mathrm{B}} \subseteq{ }_{\mathrm{X}, \mathrm{A}, \mathrm{B}} \neq_{\emptyset}$ are disjoint $\mathbf{\mathrm { t }}_{\text {-dense sets such that } \mathrm{A}} \mathrm{U}_{\mathrm{B}}=_{\mathrm{X}}$

2. Focal resolvable if there exist non empty disjoint $\mathcal{F} \mathrm{O}_{\text {dense sets } \mathrm{A}, \mathrm{B} \text { such that } \mathrm{X}}={ }_{\mathrm{A}} \mathrm{U}_{\mathrm{B}}$

3. $\oint_{\text {resolvable if there exist non empty }} \oint_{\text {dense sets A, B such that }} \mathrm{A} \bar{\delta} \mathrm{B}$ and $\mathrm{A} \delta \mathrm{B}^{\mathrm{c}}$

1. Proposition (4-15) :

Let $\left(X, T, I_{)}\right.$is $\mathbf{i}_{\text {-Topological space and }}(\mathrm{X}, \delta)$ is a proximity space if $\mathrm{X}$ is Focal resolvable then $\mathrm{X}$ is $\mathbf{i}_{\text {-resolvable. }}$

Proof :

By proposition (4-2)(1) the result exist

Example (4-16) :

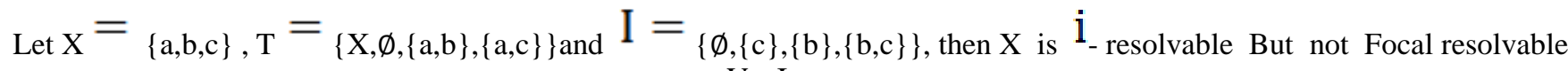

\section{Definition (5-1) :} $\mathrm{V}$ - IDEAL LINK

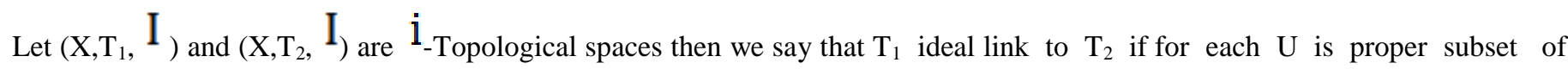
$\mathrm{X}$ in $\mathrm{T}_{1}$ there exist a proper subset of $\mathrm{X}, \mathrm{V}$ in $\mathrm{T}_{2}$ Such that $\mathrm{U} \alpha \mathrm{V}$ If $\mathrm{T}_{1}$ is ideal link to $\mathrm{T}_{2}$ we denoted that by $\mathrm{T}_{1} \gamma \mathrm{T}_{2}$

Example (5-2) :

Let $X={ }_{\{a, b, c\}, T_{1}}={ }_{\{X, \emptyset,\{a\}\} \text { and } T_{2}}={ }_{\{X, \emptyset,\{a\},\{b\}\} \text { if }} I={ }_{\{\varnothing,\{c\}\}}$

That $\mathrm{T}_{1} \chi \mathrm{T}_{2}$ But $\mathrm{T}_{2}$ is not ideal link to $\mathrm{T}_{1}$

Proposition (5-3) :

Let $\left(\mathrm{X}, \mathrm{T}_{\mathrm{j}}, \mathrm{I}\right), \mathrm{j}=1,2$ are $\mathrm{i}-$ topological spaces If $\mathrm{T}_{1} \subseteq_{\mathrm{T}_{2}}$ then $\mathrm{T}_{1} \curlyvee \mathrm{T}_{2}$

proof:

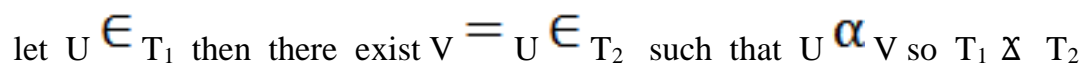

The converse of the above Proposition is not true as in the fallowing example

Example (5-4) :

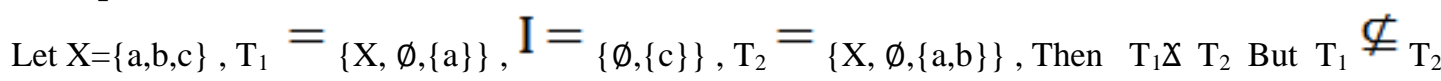

Proposition (5-5) : 
Let $\left(\mathrm{X}, \mathrm{T}_{\mathrm{j}}, \mathrm{I}\right), \mathrm{j}=1,2$ are $\mathrm{i}-$ topological spaces and $\mathrm{I} \neq\{\emptyset\}_{\text {If } \mathrm{T}_{1}} \subseteq \mathrm{T}_{2}$ then

$\mathrm{I}_{\oint_{\mathrm{T}_{1}(\mathrm{x})}} \subseteq \mathrm{I}_{\oint_{\mathrm{T}_{2}(\mathrm{x})}}$

Remark (5-6) :

$\left(\mathrm{X}, \mathrm{T}_{\text {ind }}, \mathbf{I}\right.$ ) when $\mathbf{I}$ is ang ideal on $\mathrm{X}$ is ideal link to any $\mathbf{i}$-Topological space on $\mathrm{X}$

Proposition (5-7) :

Let $\left(\mathrm{X}, \mathrm{T}_{\mathrm{j}}, \mathrm{I}_{)}, \mathbf{j}={ }_{1,2 \text { are }} \mathbf{i}_{\text {-Topological spaces then } \mathrm{T}_{1} \chi \mathrm{T}_{2} \text { iff for each } \mathrm{A}} \in_{\mathrm{T}_{1} \text { there exist } \mathrm{B}} \in_{\mathrm{T}_{2}, \mathrm{~A}} \subseteq_{\mathrm{B}}\right.$

Proof:

Let $\mathrm{A} \in_{\mathrm{T}_{1} \text { and }} \mathrm{x} \in \in_{\mathrm{A} \text { hence there exist } \mathrm{B}} \in_{\mathrm{T}_{2} \text { such that } \mathrm{A}} \alpha_{\mathrm{B}}$ that is

${ }_{\mathrm{A}} \cap \mathrm{B}_{\mathrm{B}} \in I_{\text {now }}$ If possible that $\mathrm{x} \notin_{\mathrm{B}}$, then, $\mathrm{X} \in \in_{\mathrm{B}^{\mathrm{c}} \text { that is }\{\mathrm{x}\}} \in \mathrm{I}_{\text {, for each }} \mathrm{X} \in \in_{\mathrm{A}}$, so we get that $\mathrm{A} \in \mathrm{I}_{\text {which is }}$ contradiction and therefore $\mathrm{A} \subseteq$ B.

Conversely, let $\mathrm{A} \in_{\mathrm{T}_{1} \text { so there exist, } \mathrm{B}} \in_{\mathrm{T}_{2} \text { and } \mathrm{A}} \subseteq_{\mathrm{B}}$ which meaning that ${ }_{\mathrm{A}} \cap_{\mathrm{B}^{\mathrm{c}}}={ }_{\varnothing}$ imply ${ }_{\mathrm{A}} \alpha_{\mathrm{B}}$ Then $\mathrm{T}_{1} \gamma$ $\mathrm{T}_{2}$

Proposition (5-9) :

Let $\left(\mathrm{X}, \mathrm{T}_{\mathrm{i}}, \mathrm{I}_{)} \mathbf{\mathrm { i }}={ }_{1,2}\right.$ are $\mathbf{i}_{\text {-Topological space and }}(\mathrm{X}, \boldsymbol{\delta})_{\text {such that }} \mathbf{I} \neq \neq_{\{\varnothing\} \text { and } \mathrm{T}_{1}} \subseteq \mathrm{T}_{2}$ Then

$\oint_{\mathrm{T}_{2}}(\mathrm{~A}) \subseteq \oint_{\mathrm{T}_{1}}(\mathrm{~A})$

${ }_{(2)} \mathcal{F} \mathrm{d}_{\mathrm{T}_{2(\mathrm{~A})}} \subseteq \mathcal{F} \mathrm{d}_{\mathrm{T}_{1(\mathrm{~A})} \text {. }}$

(3) $\mathcal{F a d h}_{\mathrm{T}_{2(\mathrm{~A})}} \subseteq \mathcal{F}^{\mathcal{F a d h}_{\mathrm{T}_{1(\mathrm{~A})} \text {. }}}$

(4) Every $\mathcal{F} \mathrm{O}_{\text {dense with respect to } \mathrm{T}_{2} \text { is }} \mathcal{F} \mathrm{O}_{\text {dense with respect to } \mathrm{T}_{1}}$

(5) If $X$ is focal resolvable with respect to $T_{2}$ then $X$ is focal resolvable with respect to $T_{1}$

Proof:(4) let A is $\mathcal{F} \mathrm{O}_{\text {dense with respect to } \mathrm{T}_{2} \text { and by (2) A is }} \mathcal{F} \mathrm{O}_{\text {dense with respect to } \mathrm{T}_{1}}$

Example: (5-9)

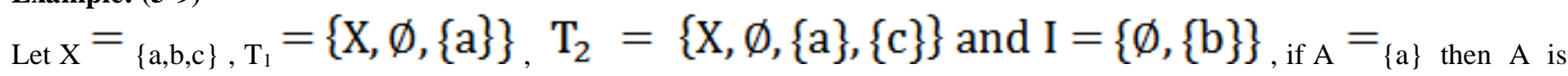
$\mathcal{F O} \mathrm{T}_{\mathrm{T} 1}$ dense But not $\mathcal{F} \mathrm{O}_{\mathrm{T} 2}$ dense

Example: (5-10)

Let $\mathrm{x}=\{\mathrm{a}, \mathrm{b}, \mathrm{c}\} \quad, \quad \mathrm{T}_{1} \quad=\quad\{\mathrm{X}, \emptyset,\{\mathrm{a}, \mathrm{b}\}\}$

$\mathrm{T}_{2}=$

$\{\mathrm{X}, \emptyset,\{\mathrm{a}\},\{\mathrm{b}\},\{\mathrm{b}, \mathrm{a}\}\}$ and $\mathrm{I}=$

$\{\emptyset,\{b\}\}$, then $X$ is $T_{1}$ - Focal resolvable But not $T_{2}$ - Focal resolvable

CONCLUSION :

1. the definition of density in $i$ - topological spaces with respect to proximity space showed some effects through the application in some theories and properties that have been studied as well as some concepts such as .

2. the concept of ideal link between two $\mathrm{i}$ - topological spaces presented in this paper is another from of the concept of coarser and finer in the previously defined topological spaces

3. Within the environment in which you work, we can apply the previous definitions in a set of concepts used by some researchers, such as the concept of w-open[17,18,19] and Para compactness [15,16], as well as the concept of soft set $[1,12,13]$ and the concept of gem set [14].

References 
[1] A.S.A.Alrazzaq, L.A.A.Al-swidi ,"soft generalized vague set and application in medical diagnosis" journal of public health research and development ,2019.

[2] Almohmmed R. ,Al swidi , L . A-A "New concepts of fuzzy local function", 17 (2). Baghdad science Journal , pp 515 -522 , 2020

[3] Abdl sada D.A ,Alswidi L.A.A. "separation axioms of center topological space", journal of advance research in Dynamical and control system , 8 (5) 1389-1393, 2020.

[4] Abdul sada D.A ,Al swidi L. AA, "some properties of c-topological space" , first international conference of computer and applied science, 52-56, 2019 .

[5] Al-swidi L.A., Al-Rubaye M.s, " New classes of separation axiom via special case of local function" , international Journal of mathematical analysis vol : (1) No - (23), 1119-1131, 2014

[6] B. C. Tripathy and G. C. Ray, "Mixed Fuzzy ideal topological spaces, Appl. Math. Comput.220(2013) 602-607

[7] Irina Zvina, "On i-topological spaces: generalization of the concept of a topological space via ideals ", Applied General Topology, Volume 7, No. 1, 2006

[8] zzettin Demir, Oya Bedre Özbakır and İsmet Yıldız, Some Properties of Fuzzy Soft Proximity Spaces, Scientific World Journal , Volume 2015

[9] K. Kuratowski, "Topologie I", Warszawa, 1933.

[10] Riesz, F. (1909), "Stetigkeit und abstrakte Mengenlehre", Rom. 4. Math. Kongr. 2: 18-24

[11] Larry Keh-Bai f.hu, "astudy of proximity spaces ", Thesis, Kansas State Teachers College ,1973

[12] L.A.Al-swidi , F.S.S.Auday ,"analysis on the soft bench points " IMSE , 2018.

[13] L.A.Al-swidi , F.S.S.Auday," on the soft turning points " Baghdad science journal , 2018.

[14] Luay A.AL-swidi " , Maryam A. Al-Ethary "compactness with gem -set " international journal of mathematical analysis , 2014

[15] Luay abd alhani alswidi , "on semi Para compactness in bitopological space" European journal of scientific journal , Vol.47, No.4, 2010

[16] L.A.A.Al-swidi , " on Para compactness in bitopological spaces" , European journal of scientific research , Vol.46 , No. 2 , 2010.

[17] L.A.A.Alswidi , A.M.Al-hussaini , " weak forms of w-open sets in bitopological spaces and connectedness " , European journal of scientific research, Vol.52, No.2, 2011.

[18] L.A.A.Alswidi , Mustafa H.H. , " Characterization of continuity nd compactness wit respect to weak forms of w-open sets " , European journal of scientific research , Vol.57, No.4, 2011.

[19] M.H.Hadi , M.A.A.Al-yaseen, L.A.ALswidi ,"forms weakly continuity using weak w-open sets " journal of interdisciplinary mathematics, 2010.

[20] Yiezi k. altalkany, Luay A.A. Al-Swidi, " Focal Function in i-Topological Spaces via Proximity Spaces " , Journal of Physics: Conference Series, Conf. Ser. 1591012083,2020

[21] V. A. Efremvich, "The geometry of proximity", Mat. Sb., 31 (1952), 189-200.

[22] J. Clerk Maxwell, A Treatise on Electricity and Magnetism, 3rd ed., vol. 2. Oxford: Clarendon, 1892, pp.68-73.

[23] I.S. Jacobs and C.P. Bean, "Fine particles, thin films and exchange anisotropy," in Magnetism, vol. III, G.T. Rado and H.

Suhl, Eds. New York: Academic, 1963, pp. 271-350.

[24] K. Elissa, "Title of paper if known," unpublished.

[25] R. Nicole, "Title of paper with only first word capitalized," J. Name Stand. Abbrev., in press.

[26] Y. Yorozu, M. Hirano, K. Oka, and Y. Tagawa, "Electron spectroscopy studies on magneto-optical media and plastic substrate interface,” IEEE Transl. J. Magn. Japan, vol. 2, pp. 740-741, August 1987 [Digests 9th Annual Conf. Magnetics Japan, p. 301, 1982].

[27] M. Young, The Technical Writer's Handbook. Mill Valley, CA: University Science, 1989. 